\title{
Extended trastuzumab therapy improves the survival of HER2-positive breast cancer patients following surgery and radiotherapy for brain metastases
}

\author{
YOSHIKO OKITA $^{1}$, YOSHITAKA NARITA ${ }^{2}$, TSUYOSHI SUZUKI ${ }^{1}$, HIDEYUKI ARITA $^{2}$, KAN YONEMORI $^{3}$, \\ TAKAYUKI KINOSHITA ${ }^{4}$, YASUHIRO FUJIWARA ${ }^{3}$, HITOSHI TSUDA ${ }^{5}$, YOSHIFUMI KOMOIKE ${ }^{6}$, \\ HIDEMITSU NAKAGAWA ${ }^{1}$, YASUHIRO TAMAKI ${ }^{6}$, YASUHIKO TOMITA ${ }^{7}$, \\ SOICHIRO SHIBUI ${ }^{2}$ and MOTOHIKO MARUNO ${ }^{1}$

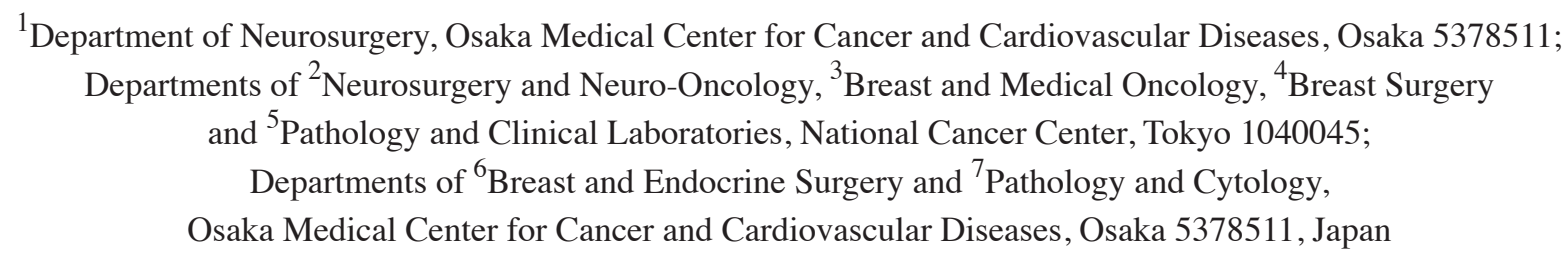

Received March 14, 2013; Accepted July 19, 2013

DOI: $10.3892 / \mathrm{mco} .2013 .162$

\begin{abstract}
Brain metastases usually present late during the course of breast cancer and are associated with an unfavorable prognosis. It was previously demonstrated that the status of estrogen receptor (ER), progesterone receptor (PR) and human epidermal growth factor receptor type 2 (HER2) may be altered in the time window between the emergence of the primary breast tumor and the development of metastases. The aim of this study was to compare the expression of ER, PR and HER2 in pathology samples of primary breast cancer and brain metastases in order to evaluate whether previously administered therapy was able to modify this status and determine whether biomarker alterations affect prognosis after the development of brain metastases. Data were collected from 62 patients who were initially diagnosed with breast cancer that had metastasized to the brain. The ER, PR and HER2 status of the samples from the primary tumors and the brain metastases was determined. Differences in the immunohistochemical profiles of ER, PR or HER2 between the primary tumors and the brain metastases in 17 patients (29.3\%) were identified. The patients with HER2-positive brain metastases who received trastuzumab had no leptomeningeal metastases and exhibited a longer survival time after brain metastases compared to the HER2-positive patients who did not receive
\end{abstract}

Correspondence to: Dr Motohiko Maruno, Department of Neurosurgery, Osaka Medical Center for Cancer and Cardiovascular Diseases, 1-3-3 Nakamichi, Higashinari-ku, Osaka 5378511, Japan E-mail:mmaruno@nsurg.med.osaka-u.ac.jp

Key words: breast cancer, brain metastases, HER2, trastuzumab, blood-brain barrier trastuzumab and the patients with HER2-negative brain metastases $(\mathrm{P}=0.0005)$. Our results suggested that the patients treated with trastuzumab following surgery and radiotherapy for brain metastases exhibited a better prognosis. Thus, the HER2 status in brain metastases requires re-evaluation and extended trastuzumab therapy is recommended after brain metastases.

\section{Introduction}

Brain metastases, including leptomeningeal metastases (LMM), usually present late during the course of breast cancer and are associated with an unfavorable prognosis. Several previous studies demonstrated that the status of estrogen receptor (ER), progesterone receptor (PR) and human epidermal growth factor receptor type 2 (HER2) is altered at a certain point between the emergence of the primary breast tumor and the development of metastases (1-5). The mechanism of this discordance in ER, PR and HER2 status between primary tumors and metastases has not been fully elucidated. It was previously reported that the majority of the tumors that do initially respond to targeted therapies may eventually develop acquired resistance (6). Other possible mechanisms are a genetic drift occurring during tumor progression (7) or intratumoral heterogeneity, wherein the clone with the more aggressive phenotype initiates the micrometastatic process $(8,9)$. The number of available pathoanatomical studies on the brain-metastasizing type of breast cancer that evaluated the extent to which the hormone and HER2 receptor discordance between paired pathology samples of primary and metastatic breast cancer specimens affect the prognosis is limited (1-5). Furthermore, few studies reported the biological marker alterations between primary tumors and brain metastases $(5,10,11)$. Post-operative adjuvant treatment decisions are commonly based on the expression of ER, PR and HER2 of 
primary tumors. Moreover, treatment decisions for recurrent brain tumor cases are generally based on the ER and HER2 status of the primary tumors. Trastuzumab is a humanized monoclonal antibody directed against the HER2/neu oncoprotein and has the ability to inhibit tumor growth in breast cancer patients overexpressing HER2 (12). However, the pharmacokinetics and effect of trastuzumab on the brain after brain metastases have not been determined. The aim of this study was to compare the expression of ER, PR and HER2 in pathology samples from primary tumors and brain metastases in order to evaluate whether the previous therapy was able to modify this status and to determine whether biomarker alterations affect prognosis after brain metastases. We also investigated the effect of trastuzumab therapy after brain metastases.

\section{Materials and methods}

Patients and tissue samples. Data were collected from 62 patients who were initially diagnosed with breast cancer and underwent surgical removal of brain metastases between 2000 and 2012 at the Osaka Medical Center for Cancer and Cardiovascular Diseases and the National Cancer Center Hospital, Japan. These patients had received treatment for primary breast cancer between 1983 and 2011 and undergone surgery for primary breast cancer and brain metastases. Tumor samples were collected from the primary resected breast cancer and metastatic brain lesions. However, not all the primary tumor samples acquired during operation at other hospitals were obtained. We only evaluated specimens considered sufficient for ER, PR and HER2 status estimation.

The ER, PR and HER2 status was determined in the samples from the primary and metastatic lesions. The first brain metastatic-free survival time was defined as the time from the first surgery for the primary tumor to the first detection of brain metastasis on magnetic resonance imaging (MRI). The second brain metastatic-free survival time was defined as the time from the first surgery for brain lesions to the second occurrence of brain metastases on MRI or patient death from any cause. LMM was diagnosed by radiological findings or the cytological evaluation of cerebrospinal fluid obtained by lumbar puncture. Detailed information on the 62 patients is provided in Table I.

This study was approved by the Institutional Review Board of each center.

Histopathological analysis. Surgical specimens were fixed in $10 \%$ formalin and embedded in paraffin. Hematoxylin and eosin-stained specimens were examined in order to determine the histological tumor type. Multiple serial sections were subjected to immunohistochemical analysis to assess local staining. Furthermore, tissue sections were subjected to $15 \mathrm{~min}$ of microwave heating to activate antigens in a retrieval solution consisting of $0.1 \mathrm{~mol} / 1$ sodium citrate $(\mathrm{pH} 6.0$ ), followed by immunostaining of the specimens with the streptavidin-biotin-peroxidase complex method (Vectastain; Vector Laboratories, Burlingame, CA, USA). Human monoclonal antibodies were used against ER (clone 1D5; Dako, Carpinteria, CA, USA) or PR (clone PgR636; Dako) with the streptavidin-biotin method and were considered positive if
Table I. Characteristics of patients with brain metastases from breast cancer.

\begin{tabular}{lccr}
\hline Characteristics & Patient no. & Years & $\%$ \\
\hline Gender & & & \\
Female & 59 & & 95.2 \\
Male & 3 & & 4.8 \\
Age at onset & & & \\
Median & & 45.5 & \\
Range & & $31-76$
\end{tabular}

Age at first

brain metastases

Median

Range

RPA classification

Class 1

14

22.6

Class 2

40

64.5

Class 3

8

12.9

Radiotherapy

WBRT

34

54.8

WBRT + LBRT

4.8

WBRT + SRS

3

21.0

LBRT

14.5

LBRT + SRS

1.6

None

3.2

Second BM

Local and distant

41.9

LMM

26

16.1

No second recurrence

35.5

Unknown

6.5

Median overall

6.5

survival

Median survival time

after BM

1.1

Median first

BM-free survival

Median second brain

BM-free survival

RPA, recursive partitioning analysis; WBRT, whole-brain radiotherapy; LBRT, local brain radiotherapy; SRS, stereotactic radiosurgery; LMM, leptomeningeal metastases; BM, brain metastases.

$\geq 10 \%$ of the nuclei in the invasive component of the tumor were stained $(13,14)$. The HER2/neu status, as assessed using the HercepTest assay (Dako), was scored by the pathologists at each center on a scale of 0 to $3+$, according to the Dako scoring system. HER2/neu positivity was defined as HER2/neu 3+ or HER2/neu 2+ and fluorescence in situ hybridization positivity.

Statistical analysis. Metastatic-free survival and overall survival (OS) times were calculated with the Kaplan-Meier method and differences between groups were compared using 
Table II. Alterations in ER and HER2 status in primary tumor and brain metastases.

Brain metastases ER/HER2 status

\begin{tabular}{lllcc} 
Primary breast cancer & & $(+/-)$ & $(-/+)$ & $(-/-)$ \\
\cline { 2 - 5 } ER/HER2 status & $(+/+)$ & $0(0 \%)$ & $2(3.4 \%)$ & $0(0 \%)$ \\
$(+/+)$ & $0(0 \%)$ & $2(3.4 \%)$ & $0(0 \%)$ & $3(5.2 \%)$ \\
$(+/-)$ & $0(0 \%)$ & $1(1.7 \%)$ & $18(31.0 \%)$ & $2(3.4 \%)$ \\
$(-/+)$ & $1(1.7 \%)$ & $3(5.2 \%)$ & $1(1.7 \%)$ & $22(37.9 \%)$ \\
\hline
\end{tabular}

ER, estrogen receptor; HER2, human epidermal growth factor receptor type 2.

the log-rank test (JMP software version 8; SAS Institute Inc., Cary, NC, USA).

\section{Results}

Metastatic-free survival and OS time. The 62 patients underwent resections of the first brain metastases. The median age at the first brain metastasis was 51 years. Thirty-four patients received whole-brain radiotherapy (WBRT). Three patients received WBRT and local brain radiotherapy (LBRT) and 13 patients received WBRT and stereotactic radiosurgery (SRS). Nine patients received LBRT and one received LBRT plus SRS. Two patients were observed without radiotherapy following surgical resection of the first brain metastases (Table I). Five of the nine patients who only received LBRT developed a second brain recurrence negative for LMM whereas the remaining four patients did not develop second brain metastases.

The median first and second brain metastatic-free survival times, the survival time after brain metastases and the OS time from the initial diagnosis of breast cancer for the 62 breast cancer patients were 4.0, 0.6, 1.1 and 6.5 years, respectively (Table I). The 5-year OS rate from surgical resection of brain metastases was $11.1 \%$. Patients with recursive partitioning analysis (RPA) (15) class I and II had a more favorable OS compared to class III patients, although RPA classes did not significantly differ in survival time after brain metastases (Fig. 1, $\mathrm{P}=0.16$ ).

Alteration of ER, PR and HER2 status in primary tumor and brain metastases. The alterations in the ER and HER2 status in primary tumors and brain metastases are presented in Table II. The positive rate of immunohistochemical profiles of ER, PR and HER2 in the primary tumors were $11.7 \%(7 / 60)$, $8.6 \%(5 / 58)$ and $41.4 \%(24 / 58)$, respectively. The positive rates of immunohistochemical profiles of ER, PR and HER2 in brain metastases were $16.1 \%(10 / 62), 11.3 \%(7 / 62)$ and $43.5 \%$ (27/62), respectively. The rates of immunohistochemical alteration of ER, PR and HER2 and triple-negative status between primary and brain metastases were $21.7 \%(13 / 60)$, $10.3 \%$ (6/58), $12.1 \%$ (7/58) and $13.8 \%$ (8/58), respectively. The immunohistochemical profiles for ER, PR and HER2 differed between the primary tumors and the brain metastases in 17 patients $(29.3 \%$; 17/58, Table III). The discordance rates in the 17 patients were $76.5 \%$ for ER, $35.3 \%$ for PR and $41.2 \%$ for

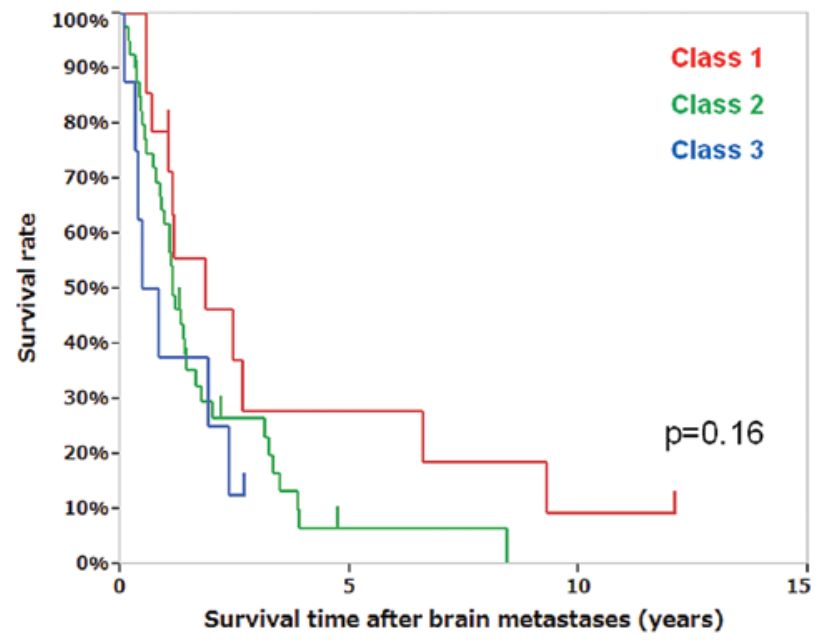

Figure 1. Overall survival from brain metastases by recursive partitioning analysis (RPA) classification. Kaplan-Meier survival curves according to RPA classification after brain metastases.

HER2 (Table III). All the patients with ER or PR alterations (positive-negative or negative-positive) had received hormone therapy prior to the development of brain metastases. Two of three patients with HER2 alteration (positive-negative) had received trastuzumab therapy prior to the development of brain metastases. A HER2-positive status was maintained in $88.9 \%(16 / 18)$ of the patients who had received trastuzumab prior to the development of brain metastases. All the patients with negative-positive alteration in HER2 had received hormone therapy but not trastuzumab prior to the development of brain metastases (Table III). One of five patients $(20.0 \%)$ with triple-negative breast cancer (TNBC) did not exhibit any status alterations in the brain metastases and had received chemotherapy prior to the development of brain metastases.

Clinical outcome with trastuzumab therapy after brain metastases. Trastuzumab was administered to 18 of 24 patients who had HER2-positive primary tumors prior to brain metastases and to 10 of these 24 patients after brain metastases. Two patients were started on trastuzumab after brain metastases.

The median first brain metastatic-free survival time of patients with a positive HER2 status in the primary tumors with $(n=18)$ and without trastuzumab $(n=6)$ was 4.2 and 
Table III. Discordance cases of immunohistochemical profiles between primary tumors and brain metastases.

\begin{tabular}{|c|c|c|c|c|c|c|c|c|c|}
\hline \multirow{2}{*}{$\begin{array}{l}\text { Case } \\
\text { no. }\end{array}$} & \multicolumn{2}{|c|}{ HER2 } & \multicolumn{2}{|c|}{ ER } & \multicolumn{2}{|c|}{ PR } & \multirow{2}{*}{$\begin{array}{c}\text { Chemotherapy } \\
\text { prior to } \\
\text { BM }\end{array}$} & \multirow{2}{*}{$\begin{array}{l}\text { Hormone } \\
\text { therapy } \\
\text { prior to } \\
\text { BM }\end{array}$} & \multirow{2}{*}{$\begin{array}{c}\text { Trastuzumab } \\
\text { therapy } \\
\text { prior to } \\
\text { BM }\end{array}$} \\
\hline & Primary & $\mathrm{BM}$ & Primary & $\mathrm{BM}$ & Primary & $\mathrm{BM}$ & & & \\
\hline 1 & - & - & - & + & - & - & - & + & - \\
\hline 2 & - & - & - & + & - & - & - & + & - \\
\hline 3 & - & - & - & + & - & + & - & + & - \\
\hline 4 & - & + & - & - & - & - & + & + & - \\
\hline 5 & - & + & - & + & - & - & - & + & - \\
\hline 6 & - & + & - & + & - & + & - & + & - \\
\hline 7 & - & + & - & + & - & + & - & + & - \\
\hline 8 & - & - & + & + & - & + & + & + & - \\
\hline 9 & - & - & + & - & + & - & - & + & - \\
\hline 10 & - & - & + & - & + & + & - & + & - \\
\hline 11 & - & - & + & - & + & + & - & + & - \\
\hline 12 & + & - & - & - & - & - & + & - & - \\
\hline 13 & + & - & - & - & - & - & + & - & + \\
\hline 14 & + & - & - & + & - & - & - & + & + \\
\hline 15 & + & + & - & + & - & - & - & + & - \\
\hline 16 & + & + & + & - & - & - & + & + & + \\
\hline 17 & + & + & + & - & + & - & + & + & - \\
\hline
\end{tabular}

HER2, human epidermal growth factor receptor type 2; ER, estrogen receptor; PR, progesterone receptor; BM, brain metastases.

A

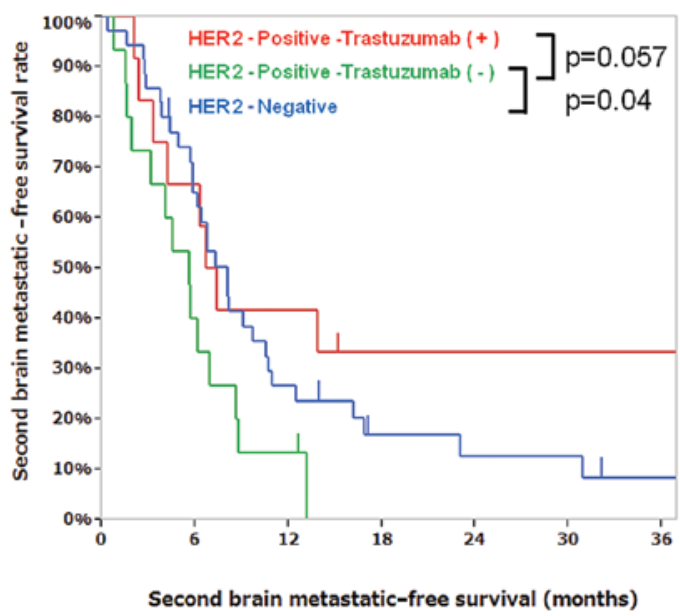

B

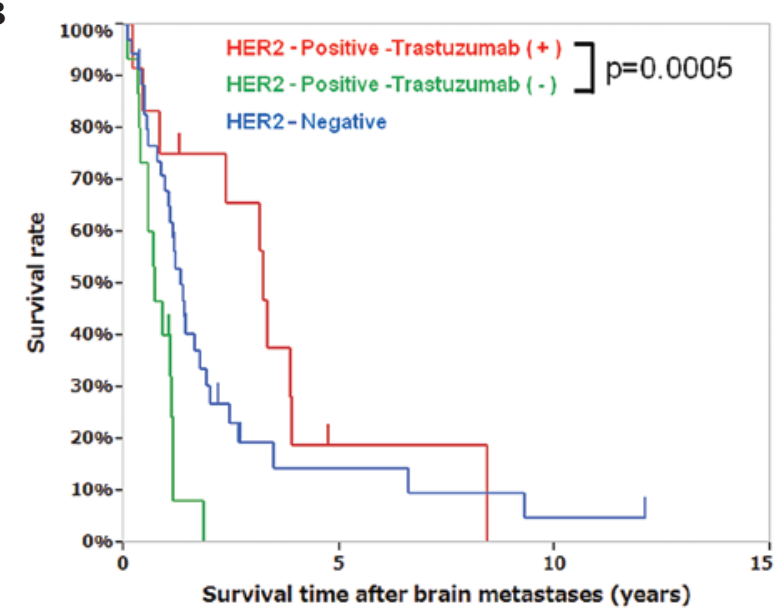

Figure 2. (A) Second brain metastatic-free survival time according to HER2 status and trastuzumab therapy after brain metastases. (B) Overall survival from brain metastases by HER2 status and trastuzumab therapy after brain metastases.

5.3 years, respectively, whereas that of patients with negative HER2 status $(n=34)$ was 4.0 years. The HER2 status in primary tumors with trastuzumab therapy prior to brain metastases did not correlate with the first brain metastatic-free survival time. The second brain metastatic-free survival time of patients with positive HER2 status in brain lesions with $(n=12)$ and without trastuzumab $(\mathrm{n}=15)$ was 7.0 and 5.6 months, respectively $(\mathrm{P}=0.057)$, whereas that of patients with negative HER2 status $(\mathrm{n}=35)$ was 8.0 months (Fig. 2A). The median OS from the first brain metastasis in patients with positive HER2 status with and without trastuzumab was 3.2 and 0.7 years, respectively ( $\mathrm{P}=0.0005$, Fig. 2B, Table IV). The HER2 status in brain metastases with trastuzumab therapy after brain metastases did not correlate with the second brain metastatic-free survival time. Compared to HER2-positive patients who did not receive trastuzumab and those with HER2-negative brain metastases, the patients who had HER2-positive brain metastases and received trastuzumab tended to have longer second brain metastatic-free survival times $(\mathrm{P}=0.057)$ and exhibited significantly longer survival times after brain metastases 
Table IV. Characteristics and survival time according to HER2 status and trastuzumab therapy after brain metastases.

\begin{tabular}{|c|c|c|c|}
\hline Characteristics & $\begin{array}{l}\text { Positive HER2 } \\
\text { with trastuzumab }\end{array}$ & $\begin{array}{l}\text { Positive HER2 } \\
\text { without trastuzumab }\end{array}$ & Negative HER2 \\
\hline Patient no. & 12 & 15 & 35 \\
\hline $\begin{array}{l}\text { Median age at first brain metastasis, } \\
\text { years (range) }\end{array}$ & $47(35-67)$ & $54(39-64)$ & $53(35-79)$ \\
\hline RPA class $1 / 2 / 3$ & $0 / 10 / 2$ & $4 / 9 / 2$ & $10 / 21 / 4$ \\
\hline ER-brain metastases +/- & $0 / 12$ & $4 / 11$ & $6 / 29$ \\
\hline PR-brain metastases +/- & $1 / 11$ & $2 / 13$ & $4 / 31$ \\
\hline $\begin{array}{l}\text { Any 2nd brain metastases including LMM } \\
\text { (within } 6 \text { months after surgery) } \\
\text { (within } 12 \text { months after surgery) }\end{array}$ & $\begin{array}{l}8(67 \%) \\
3(25 \%) \\
6(50 \%)\end{array}$ & $\begin{array}{l}7(47 \%) \\
5(33 \%) \\
7(47 \%)\end{array}$ & $\begin{array}{l}21(60 \%) \\
8(23 \%) \\
17(49 \%)\end{array}$ \\
\hline $\begin{array}{l}\text { LMM } \\
\text { (within } 6 \text { months after surgery) }\end{array}$ & $\begin{array}{l}0(0 \%) \\
0(0 \%)\end{array}$ & $\begin{array}{l}4(27 \%) \\
4(27 \%)\end{array}$ & $\begin{array}{l}6(17 \%) \\
4(11 \%)\end{array}$ \\
\hline $\begin{array}{l}\text { 2nd brain metastatic-free survival time, } \\
\text { years }(95 \% \mathrm{CI})\end{array}$ & $0.6(0.2-3.3)$ & $0.5(0.1-0.6)$ & $0.7(0.5-0.9)$ \\
\hline $\begin{array}{l}\text { Survival time after brain metastases, } \\
\text { years }(95 \% \mathrm{CI})\end{array}$ & $3.2(0.4-3.9)$ & $0.7(0.3-1.1)$ & $1.3(0.9-1.8)$ \\
\hline
\end{tabular}

HER2, human epidermal growth factor receptor type 2; RPA, recursive partitioning analysis; ER, estrogen receptor; PR, progesterone receptor; LMM, leptomeningeal metastases; CI, confidence interval.

$(\mathrm{P}=0.0005)$ (Fig. 2A and B, Table IV). Patient characteristics, including age at brain metastasis and proportion of RPA classes, were not different in the HER2-positive group with or without trastuzumab (Table IV). The ER, PR and HER2 status of brain metastatic lesions exhibited no correlation with survival time after brain metastases. There was no difference in survival time after brain metastases between TNBC and HER2-positive patients.

Trastuzumab therapy and postoperative LMM. The incidence of LMM after surgery for brain metastases was $27 \%(4 / 15)$ in patients with HER2-positive central nervous system (CNS) samples who did not receive trastuzumab and $17 \%(6 / 35)$ in patients with HER2-negative CNS samples. All the patients with LMM exhibited neuronal death. Of five patients with recurrent brain metastases who did not receive trastuzumab, four patients (80\%) developed LMM within 6 months after surgery for brain metastases. However, none of the 12 patients who were administered trastuzumab after surgery presented with LMM. Thus, trastuzumab therapy after brain metastases decreased the incidence of postoperative LMM (Chi-square test, $\mathrm{P}=0.053)$.

\section{Discussion}

Breast cancer is the second most common cause of brain metastases. Brain metastases occur in $14-20 \%$ of breast cancer patients and usually occur late in the progression of metastatic disease (16). The results of the present study have demonstrated that, among patients with HER2-positive brain metastases, those who received trastuzumab had longer survival times following surgery for brain metastases, compared to those without trastuzumab treatment.
The prolongation of the OS time in HER2-positive breast cancer patients with trastuzumab may be attributed to the decrease in LMM and neuronal death and the effects of trastuzumab on the control of systemic metastases (17-21). A positive HER2 status in primary breast cancer was considered a risk factor for the development of brain metastases (22). Although trastuzumab does not cross the blood-brain barrier (BBB) and has no direct activity on brain metastases, previous studies reported a survival benefit with trastuzumab in HER2-positive patients with brain metastases, who had a significantly longer survival compared to that of HER2-negative patients (17-21), which was consistent with our findings. Trastuzumab therapy prior to brain metastases did not correlate with the first brain metastatic-free survival time in our study, since trastuzumab therapy was not associated with an increased incidence of brain metastases $(23,24)$. The patients with HER2-positive brain metastases who received trastuzumab exhibited longer OS after brain metastases compared to the patients with HER2-positive brain metastases without trastuzumab treatment in our study. The development of LMM was a rare manifestation encountered in $5-8.1 \%$ of patients with HER2-positive primary tumors $(17,20)$. None of the patients who received trastuzumab therapy after surgery for brain metastases presented with LMM in our study. Of note, radiotherapy with doses of 20-30 Gy with a fraction size of 2 Gy was reported to increase the permeability of the BBB and may enhance the effect of chemotherapy (25). Thus, surgery followed by WBRT may disrupt the BBB and facilitate the delivery of trastuzumab to the brain in HER2-positive patients.

Hormone receptor and HER2 status are important predictive markers in breast cancer. ER negativity was associated with an increased risk of brain metastases (26-28) and HER2 
amplification/overexpression was shown to be a prognostic and predictive factor for the development of brain metastases (29). Approximately two-thirds of early breast cancer patients were found to be ER-positive (30) and the HER2-positivity rate in early breast cancer was reported to be $\sim 15 \%$ by a previous study (31). In our study, the ER and HER2-positivity rate in primary tumors was lower (11.7\%) and higher (41.4\%), respectively, compared to those reported by previous studies on primary breast tumors.

Several previous studies demonstrated that the discordance in biomarker expression between primary tumors and metastases and the alteration of hormone receptor and HER2 status is affected by adjuvant chemotherapy associated with hormone therapy and may affect the prognosis $(1-5,32,33)$. The alterations were possibly attributed to a genetic drift or clonal selection during tumor progression (7) or to the presence of intratumoral heterogeneity in ER, PR and HER2 status $(8,9)$. In previous studies that investigated primary breast cancer and distant metastases, the locoregional recurrence or lymph node metastasis, including brain metastasis, exhibited discordance rates of $0-37.5 \%$ (34-40). In our study, the immunohistochemical profiles for ER, PR and HER2 differed between the primary tumors and the brain metastases in $29.3 \%$ of the patients. Prior hormone therapy or chemotherapy exerted an effect on this discordance phenomenon (1-5,32,33). All the patients with ER or PR alterations (positive-negative and negative-positive) had received hormone therapy prior to the development of brain metastases. Negative-positive alterations were observed in $15.1 \%$ of ER-negative, $7.5 \%$ of PR-negative and $11.8 \%$ of HER2-negative primary tumors in our study. The HER 2 status was highly maintained and the concordance rate between primary tumors and systemic metastases was shown to be $97 \%$ by a previous study (41). We demonstrated that $89 \%$ of HER2-positive patients treated with trastuzumab prior to the development of brain metastases maintained a positive status in brain metastases. The possibility of the discordance rate in HER2 expression between primary and metastatic tumors was less frequent compared to ER or PR (10,11,34-40,42); however, the possibility of intratumoral heterogeneity must be considered, with re-evaluation of the HER2 status in brain metastases for further systemic treatment after brain metastases. New HER2-targeted drugs, such as lapatinib, are able to cross the BBB and thereby control brain metastases and other systemic breast cancer metastases more effectively (43).

In conclusion, $11.8 \%$ of HER2-negative patients with primary breast cancers had positive HER2 status alterations in the brain metastases. Patients treated with trastuzumab after surgery for brain metastases and radiotherapy exhibited a better prognosis. Thus, the HER2 status in brain metastases requires re-evaluation and the administration of trastuzumab or lapatinib in HER2-positive patients should be considered even after brain metastases.

\section{Acknowledgements}

This study was supported by Grant-in-Aid for Scientific Research from the Ministry of Education, Science and Culture of Japan (no. 24791520 to Y.O., no. 24592180 to Y.N.).

\section{References}

1. Bogina G, Bortesi L, Marconi M, Venturini M, Lunardi G, Coati F, Massocco A, Manfrin E, Pegoraro C and Zamboni G: Comparison of hormonal receptor and HER-2 status between breast primary tumours and relapsing tumours: clinical implications of progesterone receptor loss. Virchows Arch 459: 1-10, 2011.

2. Broom RJ, Tang PA, Simmons C, Bordeleau L, Mulligan AM, O'Malley FP, Miller N, Andrulis IL, BrennerDM and Clemons MJ: Changes in estrogen receptor, progesterone receptor and Her-2/ neu status with time: discordance rates between primary and metastatic breast cancer. Anticancer Res 29: 1557-1562, 2009.

3. Guarneri V, Giovannelli S, Ficarra G, Bettelli S, Maiorana A, Piacentini F, Barbieri E, Dieci MV, D'Amico R, Jovic G and Conte P: Comparison of HER-2 and hormone receptor expression in primary breast cancers and asynchronous paired metastases: impact on patient management. Oncologist 13: 838-844, 2008.

4. Nishimura R, Osako T, Okumura Y, Tashima R, Toyozumi Y and Arima N: Changes in the ER, PgR, HER2, p53 and Ki-67 biological markers between primary and recurrent breast cancer: discordance rates and prognosis. World J Surg Oncol 9: 131, 2011.

5. Yonemori K, Tsuta K, Shimizu C, Hatanaka Y, Hashizume K, Ono M, Nakanishi Y, Hasegawa T, Miyakita Y, Narita Y, Shibui S and Fujiwara Y: Immunohistochemical profiles of brain metastases from breast cancer. J Neurooncol 90: 223-228, 2008.

6. Johnston SR, Saccani-Jotti G, Smith IE, Salter J, Newby J, Coppen M,Ebbs SR and Dowsett M: Changes in estrogen receptor, progesterone receptor, and $\mathrm{pS} 2$ expression in tamoxifen-resistant human breast cancer. Cancer Res 55: 3331-3338, 1995.

7. Edgerton SM, Moore D II, Merkel D and Thor AD: erbB-2 (HER-2) and breast cancer progression. Appl Immunohistochem Mol Morphol 11: 214-221, 2003.

8. Kerbel RS: Growth dominance of the metastatic cancer cell: cellular and molecular aspects. Adv Cancer Res 55: 87-132, 1990

9. Pertschuk LP, Axiotis CA, Feldman JG, Kim YD Karavattayhayyil SJ and Braithwaite L: Marked intratumoral heterogeneity of the proto-oncogene Her-2/neu determined by three different detection systems. Breast J 5: 369-374, 1999.

10. Gancberg D, Di Leo A, Cardoso F, Rouas G, Pedrocchi M, Paesmans M, Verhest A, Bernard-Marty C, Piccart MJ and Larsimont D: Comparison of HER-2 status between primary breast cancer and corresponding distant metastatic sites. Ann Oncol 13: 1036-1043, 2002.

11. Sari E, Guler G, Hayran M, Gullu I, Altundag K and Ozisik Y: Comparative study of the immunohistochemical detection of hormone receptor status and HER-2 expression in primary and paired recurrent/metastatic lesions of patients with breast cancer. Med Oncol 28: 57-63, 2011.

12. Baselga J, Tripathy D, Mendelsohn J, et al: Phase II study of weekly intravenous recombinant humanized anti-p185HER2 monoclonal antibody in patients with HER2/neu-overexpressing metastatic breast cancer. J Clin Oncol 14: 737-744, 1996.

13. Harvey JM, Clark GM, Osborne CK and Allred DC: Estrogen receptor status by immunohistochemistry is superior to the ligand-binding assay for predicting response to adjuvant endocrine therapy in breast cancer. J Clin Oncol 17: 1474-1481, 1999.

14. Perren A, Weng LP, Boag AH, Ziebold U, Thakore K, Dahia PL, Komminoth P, Lees JA, Mulligan LM, Mutter GL and Eng C: Immunohistochemical evidence of loss of PTEN expression in primary ductal adenocarcinomas of the breast. Am J Pathol 155: 1253-1260, 1999.

15. Gaspar L, Scott C, Rotman M, Asbell S, Phillips T, Wasserman T, McKenna WG and Byhardt R: Recursive partitioning analysis (RPA) of prognostic factors in three Radiation Therapy Oncology Group (RTOG) brain metastases trials. Int J Radiat Oncol Biol Phys 37: 745-751, 1997.

16. Flowers A and Levin VA: Management of brain metastases from breast carcinoma. Oncology (Williston Park) 7: 21-26; discussion 31-34, 1993.

17. Bendell JC, Domchek SM, Burstein HJ, Harris L, Younger J, Kuter I, Bunnell C, Rue M, Gelman R and Winer E: Central nervous system metastases in women who receive trastuzumab-based therapy for metastatic breast carcinoma. Cancer 97: 2972-2977, 2003.

18. Kirsch DG,Ledezma CJ, Mathews CS, Bhan AK, Ancukiewicz M, Hochberg FH and Loeffler JS: Survival after brain metastases from breast cancer in the trastuzumab era. J Clin Oncol 23: 2114-2117, 2005. 
19. Le Scodan R, Jouanneau L, Massard C, Gutierrez M, Kirova Y, Cherel P, Gachet J, Labib A and Mouret-Fourme E: Brain metastases from breast cancer: prognostic significance of HER-2 overexpression, effect of trastuzumab and cause of death. BMC Cancer 11: 395, 2011.

20. Nam BH, Kim SY, Han HS, Kwon Y, Lee KS, Kim TH and Ro J: Breast cancer subtypes and survival in patients with brain metastases. Breast Cancer Res 10: R20, 2008.

21. Park IH,RoJ,LeeKS,Nam BH,Kwon Y and Shin KH: Trastuzumab treatment beyond brain progression in HER2-positive metastatic breast cancer. Ann Oncol 20: 56-62, 2009.

22. Duchnowska R, Dziadziuszko R, Czartoryska-Arlukowicz B, Radecka B, Szostakiewicz B, Sosinska-Mielcarek K, Karpinska A, Staroslawska E, Kubiatowski T and Szczylik C: Risk factors for brain relapse in HER2-positive metastatic breast cancer patients. Breast Cancer Res Treat 117: 297-303, 2009.

23. Romond EH, Perez EA, Bryant J, et al: Trastuzumab plus adjuvant chemotherapy for operable HER2-positive breast cancer. N Engl J Med 353: 1673-1684, 2005

24. Smith I, Procter M, Gelber RD, et al; HERA study team: 2-year follow-up of trastuzumab after adjuvant chemotherapy in HER2-positive breast cancer: a randomised controlled trial. Lancet 369: 29-36, 2007.

25. van Vulpen M, Kal HB, Taphoorn MJ and El-Sharouni SY: Changes in blood-brain barrier permeability induced by radiotherapy: Implications for timing of chemotherapy? (Review) Oncol Rep 9: 683-688, 2002.

26. Maki DD and Grossman RI: Patterns of disease spread in metastatic breast carcinoma: influence of estrogen and progesterone receptor status. AJNR Am J Neuroradiol 21: 1064-1066, 2000

27. Samaan NA, Buzdar AU, Aldinger KA, Schultz PN, Yang KP, Romsdahl MM and Martin R: Estrogen receptor: a prognostic factor in breast cancer. Cancer 47: 554-560, 1981.

28. Tham YL, Sexton K, Kramer R, Hilsenbeck S and Elledge R: Primary breast cancer phenotypes associated with propensity for central nervous system metastases. Cancer 107: 696-704, 2006.

29. Leyland-Jones B: Human epidermal growth factor receptor 2 -positive breast cancer and central nervous system metastases. J Clin Oncol 27: 5278-5286, 2009.

30. No authors listed: Tamoxifen for early breast cancer: an overview of the randomised trials. Early Breast Cancer Trialists Collaborative Group. Lancet 351: 1451-1467, 1998.

31. Schneeweiss A, Marme F, Ruiz A, Manikhas AG, Bottini A, Wolf M, Sinn HP, Mansouri K, Kennedy L and Bauknecht T: A randomized phase II trial of doxorubicin plus pemetrexed followed by docetaxel versus doxorubicin plus cyclophosphamide followed by docetaxel as neoadjuvant treatment of early breast cancer. Ann Oncol 22: 609-617, 2011.
32. Yonemori K, Tsuta K, Ono M, Shimizu C, Hirakawa A, Hasegawa T, Hatanaka Y, Narita Y, Shibui S and Fujiwara Y: Disruption of the blood brain barrier by brain metastases of triple-negative and basal-type breast cancer but not HER2/neu-positive breast cancer. Cancer 116: 302-308, 2010.

33. Konecny G, Pauletti G, Pegram M, et al: Quantitative association between HER-2/neu and steroid hormone receptors in hormone receptor-positive primary breast cancer. J Natl Cancer Inst 95: 142-153, 2003.

34. Gong Y, Booser DJ and Sneige N: Comparison of HER-2 status determined by fluorescence in situ hybridization in primary and metastatic breast carcinoma. Cancer 103: 1763-1769, 2005.

35. Lower EE, Glass E, Blau R and Harman S: HER-2/neu expression in primary and metastatic breast cancer. Breast Cancer Res Treat 113: 301-306, 2009.

36. Niehans GA, Singleton TP, Dykoski D and Kiang DT: Stability of HER-2/neu expression over time and at multiple metastatic sites. J Natl Cancer Inst 85: 1230-1235, 1993.

37. Pectasides D, Gaglia A, Arapantoni-Dadioti P, Bobota A, Valavanis C, Kostopoulou V, Mylonakis N, Karabelis A, Pectasides $\mathrm{M}$ and Economopoulos T: HER-2/neu status of primary breast cancer and corresponding metastatic sites in patients with advanced breast cancer treated with trastuzumab-based therapy. Anticancer Res 26: 647-653, 2006.

38. Regitnig P, Schippinger W, Lindbauer M, Samonigg H and Lax SF: Change of HER-2/neu status in a subset of distant metastases from breast carcinomas. J Pathol 203: 918-926, 2004.

39. Shimizu C, Fukutomi T, Tsuda H, Akashi-Tanaka S, Watanabe T, Nanasawa $T$ and Sugihara K: c-erbB-2 protein overexpression and p53 immunoreaction in primary and recurrent breast cancer tissues. J Surg Oncol 73: 17-20, 2000.

40. Zidan J, Dashkovsky I, Stayerman C, Basher W, Cozacov C and Hadary A: Comparison of HER-2 overexpression in primary breast cancer and metastatic sites and its effect on biological targeting therapy of metastatic disease. Br J Cancer 93: 552-556, 2005.

41. Fuchs IB, Loebbecke M, Buhler H, Stoltenburg-Didinger G, Heine B, Lichtenegger W and Schaller G: HER2 in brain metastases: issues of concordance, survival, and treatment. J Clin Oncol 20: 4130-4133, 2002

42. Liedtke C, Broglio K, Moulder S, et al: Prognostic impact of discordance between triple-receptor measurements in primary and recurrent breast cancer. Ann Oncol 20: 1953-1958, 2009.

43. Geyer CE, Forster J, Lindquist D, et al: Lapatinib plus capecitabine for HER2-positive advanced breast cancer. N Engl J Med 355: 2733-2743, 2006. 